\title{
Improvements in HOMA indices and pancreatic endocrinal tissues in type 2-diabetic rats by DPP-4 inhibition and antioxidant potential of an ethanol fruit extract of Withania coagulans
}

Heera Ram ( $\nabla$ hr.zo@jnvu.edu.in )

Jai Narain Vyas University https://orcid.org/0000-0001-6743-1321

Pramod Kumar

Jai Narain Vyas University Faculty of Science

Ashok Purohit

Jai Narain Vyas University Faculty of Science

Priya Kashyap

Guru Gobind Singh Indraprastha University

\section{Suresh Kumar}

Guru Gobind Singh Indraprastha University

\section{Shivani Kumar}

Guru Gobind Singh Indraprastha University

\section{Garima Singh}

Mizoram University Pachhunga University College

\section{Abdulaziz A. Alqarawi}

King Saud University College of Food and Agricultural Sciences

Abeer Hashem

King Saud University College of Science

\section{Elsayed Fathi Abd_Allah}

King Saud University College of Food and Agricultural Sciences

\section{Bhim Pratap Singh}

NIFTEM: National Institute of Food Technology Entrepreneurship and Management

\section{Research}

Keywords: HOMA, $\beta$-cells, Pancreatic histology, Antioxidants, DPP-4, Phytochemicals

Posted Date: January 4th, 2021

DOI: https://doi.org/10.21203/rs.3.rs-69981/v2 
License: (c) (i) This work is licensed under a Creative Commons Attribution 4.0 International License. Read Full License

Version of Record: A version of this preprint was published at Nutrition \& Metabolism on April 21st, 2021. See the published version at https://doi.org/10.1186/s12986-021-00547-2. 


\section{Abstract}

Context: Withania coagulans (Stocks) Dunal fruits are used in the therapeutics of several ailments due to possessing of potent phytoconstituents which is also used traditionally for curing the diabetes.

Objective: The present study was assessing the amelioration potential of the phytochemicals of an ethanol fruit extract of Withania coagulans (Stocks) Dunal in the HOMA (Homeostatic model assessment) indices and pancreatic endocrinal tissues by inhibition of DPP-4 and antioxidants activities.

Material and methods: The identification of phytoconstituents of the test extract was performed by LCMS. Further, assessments of in-vitro, in-vivo and in-silico were achieved by following standard methods. In-vivo studies were conducted on type-2 diabetic rats

Results: The chosen extract inhibited DPP-4 activity by $63.2 \%$ in an in vitro assay as well as significantly inhibit serum DPP-4 levels. Accordingly, the administration of the ethanol fruit extract resulted in a significant $(P \leq 0.001)$ alterations in the lipid profile, antioxidant levels, and HOMA indices. Moreover, pancreatic endocrinal tissues (islet of Langerhans) appeared to have the restoration of normal histoarchitecture as evidenced by increased cellular mass. Molecular docking (Protein - ligands) of identified phytoconstituents with DPP-4 (target enzyme) shown incredibly low binding energy (Kcal/mol) as required for ideal interactions. ADMET analysis of the pharmacokinetics of the identified phytoconstituents indicated an ideal profile as per Lipinski laws.

Conclusion: It can be concluded that the phytoconstituents of an ethanol fruit extract of Withania coagulans have the potential to inhibit DPP-4 which result in improved glucose homeostasis and restoration of pancreatic endocrinal tissues in type-2 diabetic rats.

\section{Introduction}

Diabetes Mellitus is chronic and complex metabolic disorder in which the role of the DPP-4 enzyme has been established. DPP4 rapidly degrades GLP-1(glucagon like Peptide-1)and plays a crucial role in glucose homeostasis[1]. DPP4 inhibitors block the degradation of GLP-1, the latter of which is responsible for stimulating insulin secretion, and thus plays a significant role in regulating glucose homeostasis[2]. The present study assessed the antidiabetic potential of an ethanol fruit extract of Withania coagulans. The use of herbal medicines based on historical knowledge has gained greater acceptance throughout the world[3]. The use of plants in herbal medicine represents a reservoir of historic information that has been developed over countless generations[4,5]. The Ayurvedic medicine, traditional Chinese medicine (TCM) and integrative medicine represent a significant Asian legacy based on thousands of years of research and healthcare[6].

Information from several studies suggest that the various phytoconstituents present in plants, such as the flavonoids, saponins, tannins, alkaloids, glycosides, and terpenes, possesses anti-diabetic properties[7]. The anti-diabetic effect of the phytocompounds has been proposed to be based on several 
mechanisms working alone or in parallel, including stimulation of insulin secretion, reduction in hepatic glucose uptake, inhibition of enzymes involved in carbohydrate metabolism (such as a-glucosidase inhibitors), modulation of molecules such as PPARy, hypolipidemic action, antioxidant potential, interference with the action of glycolytic enzymes (such as phosphoenolpyruvate), carboxykinase activity, and augmentation of the expression of glucose transporters, etc.[8].

In this regard, the fruit of Withania coagulans has gained interest for its antidiabetic activity in some animal models, as well as in pilot trials in humans[9-11]. W. coagulans fruit possesses a variety of bioactive phytoconstituents that vary in their polarity, solubility, and specific chemical and physical properties[11]. Phytochemical studies have reported that the main phytoconstituents of the fruit are esterases, free amino acids, fatty oils, essential oils, and withanolides[12]. The withanolides, which are steroidal lactones with an ergostane skeleton, represent the predominant phytoconstituents present in $W$. coagulans fruit[13].

Previous studies have reported that $W$. coagulans fruit has been used for a variety ethnomedicinal uses, including anti-inflammatory, cardiotonic activity, hepatoprotective, antifungal, hypoglycemic, free-radical scavenging activity, hypolipidemic, wound healing activity, and for the treatment of diabetic nephropathy[9]. Extracts obtained from different parts of $W$. coagulans fruit contain a different profile of phytoconstituents. Notably, a systematic in-vitro, in-vivo, and in-silico analyses of the specific phytoconstituents present in an ethanol extract of Withania coagulans fruit has not been conducted. Therefore, the objective of the present study was to evaluate the ability of an ethanol extract of Withania coagulans fruit to maintain glucose homeostasis and restore the histology of endocrinal pancreatic tissues in type 2 diabetic rats through its inhibitory effect on DPP-4 and its antioxidant potential.

\section{Materials And Methods}

\section{Experimental design}

The experimental design was formulated in comparison to the control and treated groups where each group consisting of six wistar rats (Rattus norvegicus) $(n=6)$ with twice repeated schedule. The treatments were performed by oral administration for four weeks and these groups were compared to the vehicle (non-treated, normal metabolism) and diabetic control groups. The treated groups were received the ethanol fruit extract of Withania coagulans and the standard diabetic drug, sitagliptin. The protocols used in the animal experiments were approved by the IAEC (Institutional Animal Ethical Committee) as per norms of the CPCSEA (Committee for the Purpose of Control and Supervision of Experiments on Animals), Government of India (Reg. No.1646/GO/a/12/CPCSEA valid up to 27.03.23).

\section{Induction of type-2 diabetes}

Type-2 diabetes was induced in the rats through administration of a high-sucrose diet along with highcarbohydrate food for three weeks. Four intraperitoneal injections of dexamethasone $(1.0 \mathrm{mg} / \mathrm{kg})$ at alternate day intervals was also used to induce type 2-diabetes in the rats by following modified 
protocol[14]. The establishment of type-2 diabetes in the rats was determined by monitoring the levels of glucose and insulin through HOMA (Homeostasis Model Assessment) indices (HOMA - IR(insulin resistance), HOMA- $\beta \%$ ( $\beta$-cell function), and HOMA-S\% (insulin sensitivity)[15].

\section{Fruit extract, standard drug, and chemical reagents}

The ethanol fruit extract of Withania coagulans was prepared using a standard Soxhlet protocol. The obtained extract was subsequently evaporated to dryness in a vacuum and the dried powder was used to formulate the extract[16]. The sitagliptin (Januvia ${ }^{\circledR} 50 \mathrm{mg}$ ), was purchased from a local pharmacy in Jodhpur, India. The dose of extract $(400 \mathrm{mg} / \mathrm{kg})$ was provided to the treated rats as per calculations of physiological dose[17]. Chemical reagents were purchased from a local supplier and were of a chemical grade equal to Loba Chemie Pvt Ltd. Biomedical diagnostic kits (Erba, Pvt Ltd) were used for the biochemical analysis of blood serum and DPP-4 inhibition assay kit (Sigma Aldrich) was used for the DPP-4 inhibition assay.

\section{Identification of the phytoconstituents present in the ethanol extract of W. coagulans fruit by LC-MS analysis}

The phytoconstituents present in the ethanol extracts of $W$. coagulans fruit were identified by LCMS(Liquid chromatography and Mass spectroscopy) analysis using standard protocols[18]. The LC-MS analysis was outsourced to CDRI (Central Drug Research Institute), Lucknow, India and performed by trained technicians on the appropriate equipment (ID: FEE-2, SAIF920). The HPLC samples were further analysed by Q-TOF mass spectrometry equipped with an ESI source. The analysis conditions were as follows: Full-scan mode from $\mathrm{m} / \mathrm{z} 50$ to 1200 and a source temperature of $140^{\circ} \mathrm{C}$. The solvent was methanol with $0.3 \%$ formic acid. Solvents were subjected to a flow rate of $0.1 \mathrm{~mL} / \mathrm{min}$. The MS spectra were acquired in the positive ion mode. The mass fragmentations were identified using the spectrum database and mass hunter software.

\section{Inhibition of DPP-4 activity and treatment of hyperglycemia}

Two groups of rats were used to assess the impact of treatments on type 2- diabetic rats. The ethanol extract of $W$. coagulans fruit and the standard drug, sitagliptin, were the two assessment treatments groups. Group - III (WCEt) the formulated fruit extract at a dose of $400 \mathrm{mg} / \mathrm{kg}$ BW (Body Weight) per day was administered to type -2 diabetic rats[19]. Group -IV (SITA) sitagliptin at a dose of $50 \mathrm{mg} / \mathrm{kg}$ body weight per day, which is equivalent to a $50 \mathrm{mg}$ oral clinical dose, was administered to another group of type 2 - diabetic rats. Group - I (VC) and Group II (DC) rats were served as negative and positive controls, respectively. The extract and drug administration were performed by gastric intubation between 10 and $11 \mathrm{AM}$ to avoid variable responses due to circadian rhythms.

In-vitro and in-vivo (serum) inhibition assay of DPP-4 
The in-vitro DPP-4 assay was performed using the standard protocol of measuring chromatophore production by the cleavage of Gly-Pro p-nitroanilide hydrochloride. The inhibition of DPP-4 by the phytoconstituents of fruit extract was determined by measuring the release of 4-nitroaniline from an assay mixture that included $0.1 \mathrm{M}$ Tris- $\mathrm{HCl}(\mathrm{pH} 8.0)$ and $2 \mathrm{mM}$ Gly-Pro $p$-nitroanilide (substrate). The reaction mixture was incubated at $37^{\circ} \mathrm{C}$ and moderated by the addition of sodium acetate buffer $(\mathrm{pH} 4.5)$. Absorbance was measured at $405 \mathrm{~nm}$ using a UV-VIS Spectrophotometer[20,21]. Percent inhibition was calculated using the following formula.

\section{$\%$ inhibition $=\frac{\text { Absorbance of control }- \text { Absorbance of inhibitor }}{\text { Absorbance of Control }} \times 100$}

Accordingly, the serum DPP-4 assay was performed by following the above mentioned protocol with replacement of test sample of WC fruit by $10 \mu \mathrm{L}$ of serums from the experiment groups as reported by earlier studies[22,23].

\section{Biochemical analysis of blood serum}

a. Basic parameters: The serum parameters measured by using standard methods included glucose[24], total protein[25], insulin[26], total cholesterol[27], HDL-cholesterol[28], triglyceride[29], SGOT[30], SGPT[30], urea[31], uric acid[32], and creatinine[33]. The lipid profile (total cholesterol, HDL-cholesterol, LDL-cholesterol, Triglyceride and VLDL - cholesterol) was assessed following Friedewald's formula[3436].

LDL-C $(\mathrm{mg} / \mathrm{dL})=\mathrm{TC}(\mathrm{mg} / \mathrm{dL})-\mathrm{HDL}-\mathrm{C}(\mathrm{mg} / \mathrm{dL})-\mathrm{TG}(\mathrm{mg} / \mathrm{dL}) / 5$.

b. Total antioxidant capacity (FRAP)[37], catalase [38], SOD [39], GSH [40], and LPO activity[41] were assessed by following the standard methods.

\section{HOMA (Homeostatic model assessment) analysis}

a. (HOMA-IR and HOMA- $\beta$ ) scores and insulin sensitivity were determined using fasting serum insulin and glucose concentrations measured at the end of the experiment. Calculations were based on the formula reported by Matthew et al. (1985) and Parekh et al. (2005) as follows[42,43]. 


\section{HOMA - IR $=\frac{\text { Fasting Insulin }(\mathrm{U} / \mathrm{L}) \times \text { Fasting Glucose }(\mathrm{mmol} / \mathrm{L})}{22.5}$}

$$
\text { HOMA }-\beta=\frac{20 \times \text { Fasting Insulin }(\mathrm{U} / \mathrm{L})}{\text { Fasting Glucose }(\mathrm{mmol} / \mathrm{L})}-3.5
$$

Insulin sensitivity $(\mathrm{IS})=\frac{1}{\left[\left(\operatorname{Insulin}\left(\frac{\mathrm{U}}{\mathrm{L}}\right) \times \log (\text { glucose }(\mathrm{mmol} / \mathrm{L}))\right]\right.}$

\section{Histopathology}

Pancreatic tissues were obtained from autopsied animals after the completion of the experiments and processed for histological examination using standard methods[44]. Briefly, tissues were fixed in $10 \%$ formalin, gradually dehydrated in an ethanol series, and embedded in paraffin wax. The embedded tissues were sectioned at a 5- $\mu \mathrm{m}$ thickness, stained with hematoxylin and eosin, and were then subsequently observed with a clinical microscope and photomicrographs were taken with an attached camera.

\section{Molecular Docking analysis}

The phytoconstituents identified by LC-MS analysis and the protein ligand molecular docking with the DPP-4 protein was assessed[45,46]. Molecular interactions of the identified compounds with DPP-4 were investigated using PyMol and Autodock 4.2. The catalytic triad of DPP-4 comprises Glu205, Glu206, and Tyr226 as the main residues and a hydrophobic core is composed of ten residues (Tyr547, Tyr667, Asn710, Val711, His740, Ser630, Ser209, Arg358, Phe357, and Val207). A high-resolution crystallographic structure of DPP-4 receptor protein (PDB ID 5y7k) was downloaded from a public protein database and processed using PyMol to extract the co-crystallised ligand inhibitor, remove water molecules, and correct the chain integration. Three-dimensional structures of the identified compounds sitagliptin, and vildagliptin (two standard drugs with DPP-4 inhibitory activity) were downloaded from the Pubchem Database. Ligands were processed using PyMol and hydrogen was added to the structures. The developed docking protocol was validated by performing re-docking with prepared co-crystalized ligand and receptor protein and maps were generated. Post-validation was conducted of the docking protocol of the individual identified compounds with DPP-4 protein. Molecular interactions, ligand conformations, and binding energies for each of the phytoconstituents and the standard drugs were obtained.

\section{ADMET analysis}

ADME/T (Absorption, distribution, Metabolism, Excretion, and Toxicity) analysis was performed using Drulito software (www.niper.gov.in/pi_dev_tools/DruLiToWeb /DruLiTo_index.html) to study the 
pharmacokinetics profile of the identified compounds for potential drug development[47,48]. The compounds were ranked based on two filters: the Lipinski rule and the ability to pass through the blood brain barrier (BBB). The Lipinski rule states that an ideal drug molecule should weigh below $500 \mathrm{~g} / \mathrm{mol}$, hydrogen bond donors should be $\leq 5$, and the number of hydrogen bond acceptors should be $\leq 10$ and have a partition coefficient $\leq 5$. A compound with these properties would pass the BBB if the number of hydrogen bonds present is between 8-10 and no acidic groups are present in the molecule. TPSA (total polar surface area) indicates the bioavailability of the drug molecule as per Veber's rule. ATPSA $\leq 140 \AA$ indicates good oral bioavailability.

\section{Statistical Analysis}

Values obtained for the biochemical assessments and other data were expressed as a mean \pm the standard error of mean (SEM) and the effect of treatment was analyzed by a one-way ANOVA with a post hoc Dunnett's $t$-test using SPSS 22 trial version for windows[49]. The probability of significant differences between treatment means was set at $p \leq 0.05$.

\section{Results}

Assessments of the in-vitro, in-silico, and in-vivo activity of the fruit extract in comparison to standard diabetic drugs and relevant controls were conducted. The identification of the major phytoconstituents present in the ethanol fruit extract of $W$. coagulans was also determined by phytochemical assessments of LCMS.

\section{In - vitro inhibition of DPP-4 activity}

The in-vitro DPP-4 assay of the test extract shown $63.2 \%$ inhibition at $40 \mathrm{mg} / \mathrm{mL}$. The positive control, sitagliptin, exhibited $91.7 \%$ inhibition (Figure 1A \& 1B).

\section{Serum DPP-4 activity assay}

The serum levels of DPP-4 were significantly $(P \leq 0.001)$ elevated in type 2 diabetic control group (DR) in comparison to vehicle control animals. Whereas the treatments of the test extract and sitagliptin caused alterations in comparison to diabetic control and vehicle control (Figure 2).

\section{LC-MS identification of the phytoconstituents present in an ethanol extract of Withania coagulans fruit}

Several phytochemicals were detected in the positive mode of LC-MS analysis, including withanolide D, sitoindoside IX, withanoside IV, withanone, withanolide B, and withaferin A. Accordingly, the negative mode of LC-MS analysis identified four major compounds, withasomnine, withangulatin A, withacoagulin $\mathrm{H}$, and withanolide $\mathrm{E}$ (Figure 3A\&3B; Table 1A \&1B).

\section{Glucose homeostasis HOMA assessments of glucose homeostasis}


Treatment of the type-2 diabetic rats with the test extract resulted in significant $(P \leq 0.001)$ beneficial alterations in glucose and insulin levels. Insulin resistance was significantly higher in the diabetic control group, while treatment with the fruit extract and sitagliptin resulted in a significant reduction in insulin resistance. Concomitantly, $\beta$ - cell function and insulin sensitivity significantly increased in the fruit extract and sitagliptin treatment groups (Figure 4).

\section{Alterations in the lipid profile}

Significantly $(P \leq 0.001)$ higher levels of total cholesterol, LDL-cholesterol, VLDL-cholesterol, and triglyceride, relative to the vehicle control and treatment groups, were observed in the diabetic control group. Treatment of the diabetic rats with the fruit extract resulted in a significant reduction in total cholesterol, LDL-cholesterol, VLDL-cholesterol, and triglyceride in comparison to the diabetic control group, as well as the sitagliptin-treatment group (Figure 5).

\section{Antioxidants levels}

The level of lipid peroxidation and total protein levels were significantly $(P \leq 0.001)$ higher in the diabetic control group, relative to the vehicle control group of animals, while the levels of catalase, GSH, and SOD were significantly reduced $(P \leq 0.001)$. The treatment of the diabetic animals with fruit extract resulted in a significant increase in the levels of GSH, SOD, and catalase, relative to the diabetic control group, as well as reduced levels of lipid peroxidation (Figure 6).

\section{Histopathology of pancreas}

Shrinkage and necrosis of the nuclei of islet cells and other degenerative symptoms were observed in pancreatic cells of the diabetic control group, relative to the vehicle control (Figure 7A \& 7B). In contrast, treatment of diabetic rats with the fruit extract resulted in a significant increase in islet cellular mass in pancreatic tissues, relative to the diabetic control and the sitagliptin-treatment groups. The treatment of the diabetic rats with either the fruit extract or sitagliptin also resulted in restoration of vascular tissues (Figure 7C \&7D).

\section{In-silico molecular docking analysis}

In-silico analysis of the small molecule phytochemicals of the teat extract and target protein made by following molecular docking (Protein-ligand) and ADME/T analyses. DPP-4 has a catalytic triad comprising Glu205, Glu206 and Tyr226 residues. The molecular interactions between the various identified phytoconstituents present in the fruit extract and the DPP-4 enzyme molecule were analyzed using AutoDock 4.2.6 software. Results indicated a variable degree of hydrogen bonding with the DPP-4 enzyme ranging from moderate to strong by the different phytochemicals present in the fruit extract. The identified compounds interacted with the main catalytic site residues with strong binding energies ranging from -7.2 to $-9.8(\mathrm{Kcal} / \mathrm{mol})$; thus, inhibiting the protein irreversibly (Table 2$)$. 
The phytochemicals present in the fruit extract exhibited stronger binding energies than the positive control (sitagliptin). Molecular interaction of the phytochemicals with the catalytic site residues by hydrogen bond formation was also detected in the molecular docking analysis (Figure 8A-8I).

\section{ADMET analysis}

ADMET analysis of the identified phytoconstituents revealed that withasomnine was the only withanolide that met the Lipinski rule of five and had the potential to cross the BBB. Other withanolides and alkaloids met the Lipinski rule of an ideal drug but were determined to be unable to cross the BBB, which was most likely due to their large molecular size. (Table 3). Sitoindoside IX and withangulatin-A violated the Lipinski rule of an ideal drug molecule and could not cross the BBB filter in the ADMET analysis.

\section{Discussion}

The secretion of insulin regulated by postprandial stimulation and volume of the pancreatic $\beta$-cellular mass which is distressed by several mechanisms in type -2 diabetes[50]. The pancreatic $\beta$-cells are intricately controlled to constant activities and respond to nutrients, beneath the inflection of extra neurohormonal signals, in demand to secrete insulin to greatest encounter the requirements of the organism. The $\beta$-cell and nutrients recognizing involves multifaceted mechanisms of metabolic stimulation, ensuing in yield of stimulus-secretion linked signals that endorse insulin biosynthesis and release[50,51]. In the current study, it was seen that high sucrose diet and corticosteroid caused insulin resistance and imbalanced glucose homeostasis which may following the several pathways and resulted in decreased $\beta$-cell mass and improper postprandial stimulations by degraded activities of GLP-1 [52]. The characterized hyperglycemia of diabetic condition is also causing glucotoxicity and lipotoxicity along with insulin resistance which further resulted in apoptosis of $\beta$-cells[53]. Whereas, the treatments of the test extract ( $W$. coagulans fruit ethanol extract) and standard drug caused significant reductions in glucose, insulin and HOMA indices resulted in improvements in glucose homeostasis and increased pancreatic $\beta$-cell mass. These kinds of results may follow the interaction with DPP-4 by possesses active metabolites (phytochemicals) of extract through prolonging the GLP-1 postprandial stimulation to pancreatic tissues as reported by several studies [54,55]. Accordingly, the results of LCMS analysis shown that occurrence of potent bioactive phytocompounds in ethanol fruit extract of Withania coagulans known as withanoids, including withanolide $D$, sitoindoside IX, withanoside IV, withanone, withanolide B, withaferin $A$, withasomnine, withangulatin $A$, withacoagulin $\mathrm{H}$, and withanolide $\mathrm{E}$. Subsequently, the invitro assay of the test extract against DPP-4 performed the $63.2 \%$ inhibition which validate the interaction with target enzyme (DPP-4) and phytocompounds. Accordingly, the serum DPP-4 activities were also increased after the treatments of test extract and sitagliptin.

In same context, it is illustrated that the phytocompounds have the ability to inhibit specific enzymes by binding to the active site within the enzyme molecule or a related mode of action[56,57]. Ideal inhibitors have a low molecular weight that can reduce or completely inhibit enzyme activity at low concentrations[55]. Several human enzyme inhibitors, such as antithrombin and antitrypsin, control 
enzyme activity in the body, and can function under normal physiological conditions. Intermediary compounds are produced, however, by some natural enzyme inhibitors in some of the metabolic pathways. The inhibition of product formation is a way of controlling or modulating substrate flux through a metabolic pathway. If enzymes are sensitive to product inhibition, the output of the pathway will be suppressed[58-62].

Administration of the fruit extract treatment to type-2 diabetic rats in the present study resulted in improved HOMA indices, as well as the restoration of normal histology in pancreatic tissues. Accordingly, the results resembles that phytochemicals have free radical scavenging capacity which may contribute to improvement in HOMA indices by reducing the generation and accumulation of free radicals[63,64]. Our study demonstrated that the fruit extract and sitagliptin treatment resulted in significant changes in blood serum chemistry, including antioxidant potential. Reduced levels of free radicals may allow tissue regeneration to occur in the pancreas of the treatment groups.

Among the major phytochemicals identified in the fruit extract of $W$. coagulans, sitoindoside IX had thehighest binding energy $(-9.8 \mathrm{Kcal} / \mathrm{mol})$ to DPP-4, which was even higher than sitagliptin. These data suggest that this compound would have the greatest inhibitory activity against DPP-4. Binding energy is evidence of the degree of positive interaction that occurs between a target molecule, such as an enzyme, and the test compound or ligand. It is also a measure of the compatibility between a compound and its intended target $[65,66]$. Sitoindoside IX and most of the other phytocompounds present in the fruit extract exhibited an ideal profile in the ADMET (Absorption, distribution, metabolism, excretion and toxicity) analysis, which indicates that the compound meets the five requirements of the Lipinski rule which is a measure of the bioavailability of a molecule and its ability to pass through the blood brain barrier $[67,68]$.

\section{Conclusion}

Results indicated that the small molecule phytochemicals exhibited in an ethanol extract of W. coagulans fruit could inhibit DPP-4 and scavenge free radicals, resulting in an improvement in the HOMA indices as well as restoration in pancreatic tissues. Therefore, the study indicating the applications of small molecule phytoconstituents of the test extract for therapeutics of type-2 diabetes by validating the further studies with higher animal models and human subjects.

\section{Declarations}

\section{Acknowledgement}

This research did not receive any specific grant from funding agencies in the public, commercial, or notfor-profit sectors. The authors would like to extend their sincere appreciation to the Researchers Supporting Project Number (RSP-2020/134), King Saud University, Riyadh, Saudi Arabia. Authors are thankful to Dr. Vijai Kumar Gupta, Group leader, Scotland Rural College, Assc, Institute of University of Edinburge EH9 3JG, Edinburge, UK for language editing of the manuscript. 


\section{Conflict of interest}

There is no conflict of interest.

\section{Funding}

This study was supported by any kind of special research grant.

\section{Authors Contributions}

HR \& SK-designed the experiments and wrote the first draft of the manuscript describing the study, GS Plant Material authentication, PK\&SK - in-vivo and in-vitro studies, PK - in-silico study and AP - Review of the Manuscript, HR \& BPS - Correspondence, AAA, AH and EFA - Review, editing and Funding.

\section{Availability of data and materials}

All data used in this study has been included in this article.

\section{Ethics approval}

The experimental protocols and design were approved by IAEC (Institutional Animal Ethical Committee) Department of Zoology, JNVU, Jodhpur which is registered under CPCSEA (Reg. No.1646/GO/a/12/CPCSEA valid up to 27.03.23).

\section{Consent for publication}

Not applicable.

\section{References}

1. Nauck MA, Meier JJ. Incretin hormones: Their role in health and disease. Diabetes, Obes Metab. 2018;20:5-21.

2. Deacon CF. Physiology and Pharmacology of DPP-4 in Glucose Homeostasis and the Treatment of Type 2 Diabetes. Front Endocrinol (Lausanne). 2019;10:1-14.

3. Tanwar A, Zaidi AA, Bhardwaj M, Rathore A, Chakotiya AS, Sharma N, et al. Herbal informatics approach for the selection of natural compounds targeting diabetes mellitus. Indian J Tradit Knowl. 2018;17:270-5.

4. Abuduli M, Aljunid S. Role of Traditional and Complementary Medicine in Universal. Malaysian J Public Heal Med. 2011;11:1-5.

5. Ikram RRR, Ghani MKA, Abdullah N. An analysis of application of health informatics in Traditional Medicine: A review of four Traditional Medicine Systems. Int J Med Inform 2015;84:988-96.

6. Yin J, Zhang H, Ye J. Traditional chinese medicine in treatment of metabolic syndrome. Endocr Metab Immune Disord Drug Targets. 2008;8:99-111. 
7. Modak M, Dixit P, Londhe J, Ghaskadbi S, Paul a DT. Indian herbs and herbal drugs used for the treatment of diabetes. J Clin Biochem Nutr. 2007;40:163-73.

8. Aba PE, Asuzu IU. Mechanisms of actions of some bioactive anti-diabetic principles from phytochemicals of medicinal plants: A review. Indian J Nat Prod Resour. 2018;9:85-96.

9. Ashutosh U, Sadhana K, Mujeeb RU. Evaluation of Antidiabetic activity of fruits of Withania coagulans in streptozotocin induced diabetic rats. J Drug Deliv Ther. 2018;8:25-8.

10. Goyal M. Traditional plants used for the treatment of diabetes mellitus in Sursagar constituency, Jodhpur, Rajasthan - An ethnomedicinal survey. J Ethnopharmacol [Internet]. Elsevier; 2015;174:3648.

11. Vandana G, Keshari BB. Withania coagulans Dunal. (Paneer Doda): a review. Int J Ayurvedic Herb Med [Internet]. 2013;3:1330-6.

12. Shukla K, Dikshit P, Shukla R, Gambhir JK. The Aqueous Extract of Withania coagulans Fruit Partially Reverses Nicotinamide/Streptozotocin-Induced Diabetes Mellitus in Rats . J Med Food. 2012;15:718-25.

13. Glotter E. Withanolides and related ergostane-type steroids. Nat Prod Rep. 1991;8:415-40.

14. Martínez BB, Pereira ACC, Muzetti JH, Telles F de P, Mundim FGL, Teixeira MA. Experimental model of glucocorticoid-induced insulin resistance. Acta Cir Bras. 2016;31:645-9.

15. Chao P-CPC, Li Y, Chang CHC-H, Shieh JPJP, Cheng JTJ-T, Cheng KCK-C. Investigation of insulin resistance in the popularly used four rat models of type-2 diabetes. Biomed Pharmacother 2018;101:155-61.

16. Poojary MM, Vishnumurthy KA, Vasudeva Adhikari A. Extraction, characterization and biological studies of phytochemicals from Mammea suriga. J Pharm Anal Xi'an Jiaotong University; 2015;5:182-9.

17. Gupta A, Jacobson GA, Burgess JR, Jelinek HF, Nichols DS, Narkowicz CK, et al. Citrus bioflavonoids dipeptidyl peptidase-4 inhibition compared with gliptin antidiabetic medications. Biochem Biophys Res Commun. Elsevier Ltd; 2018;503:21-5.

18. Rijai L, Kuncoro H, Amir M. Chemical profile by LC-MS/MS and some bioactivities from leafs of kolowe (Chydenanthus excelsus): A wild and rare plant from indonesia. J Pharm Sci Res. 2017;9:111-8.

19. Prasad SK, Kumar R, Patel DK, Hemalatha S. Wound healing activity of Withania coagulans in streptozotocin-induced diabetic rats. Pharm Biol. 2010;48:1397-404.

20. Al-Masri IM, Mohammad MK, Tahaa MO. Inhibition of dipeptidyl peptidase IV (DPP IV) is one of the mechanisms explaining the hypoglycemic effect of berberine. J Enzyme Inhib Med Chem. 2009;24:1061-6.

21. Chakrabarti R, Singh B, Narendra P, Varghese N, Vanchhawng L et al. Dipeptidyl Peptidase- IV Inhibitory Activity of Berberis aristata. J Nat Prod. 2011;4:158-63. 
22. Mohanty IR, Borde M, Kumar C S, Maheshwari U. Dipeptidyl peptidase IV Inhibitory activity of Terminalia arjuna attributes to its cardioprotective effects in experimental diabetes: In silico, in vitro and in vivo analyses. Phytomedicine 2019;57:158-65.

23. Almasri IM, Mohammad MK, Taha MO. Inhibition of dipeptidyl peptidase IV by fexofenadine: Virtual screening study. J Appl Pharm Sci. 2019;9:28-32.

24. Ambade VN, Sharma Y, Somani B. Methods for Estimation of Blood Glucose: a Comparative Evaluation. Med J Armed Forces India. 2017;54:131-3.

25. Lowry OH, Rosebrough NJ, Farr AL RR. Protein Measurement with Folin Phenol Reagent. J Biol Chem. 1951;193:265-75.

26. Yalow RS, Berson $S$ a. Assay of plasma insulin in human subjects by immunological methods. Nature. 1959;184:1648-9.

27. Allain CC, Poon LS, Chan CSG, Richmond W, Fu PC. Enzymatic Determination of Total Serum Cholesterol. Clin Chem. 1974;20:470-5.

28. Moshides JS. Kinetic Enzymatic Method for Automated Determination of HDL Cholesterol in Plasma. Clin Chem Lab Med. 1987;25:583-8.

29. Gottfried SP, Rosenberg B. Improved manual spectrophotometric procedure for determination of serum triglycerides. Clin Chem. 1973;19:1077-8.

30. Reitman S, Frankel S. A colorimetric method for the determination of serum glutamic oxalacetic and glutamic pyruvic transaminases. Am J Clin Pathol. 1957;28:56-63.

31. Wybenga DR, Di Giorgio J, Pileggi VJ. Manual and automated methods for urea nitrogen measurement in whole serum. Clin Chem. 1971;17:891-5.

32. Steele, Thomas H., Mansdorfer MC. An automated ezymatic spectrophotometric method for the determination of uric acid. Am J Cinical Pathol. 1969;53:116-20.

33. Mitchell RJ. Improved method for specific determination of creatinine in serum and urine. Clin Chem. 1973;19:408-10.

34. Jatwa R, Parmar HS, Panda S, Kar A. Amelioration of corticosteroid-induced type 2 diabetes mellitus by rosiglitazone is possibly mediated through stimulation of thyroid function and inhibition of tissue lipid peroxidation in mice. Basic Clin Pharmacol Toxicol. 2007;101:177-80.

35. Parmar HS, Bhinchar MK, Bhatia M, Chordia N, Raval I, Chauhan DS, et al. Study on gluco-regulatory potential of glimepiride sulfonamide using in silico, in vitro and in vivo approaches. Curr Pharm Des. 2014;20:5212-7.

36. Ram H, Ram H, Jatwa R, Purohit A. Antiatherosclerotic and Cardioprotective Potential of Acacia senegal Seeds in Diet- Induced Atherosclerosis in Rabbits Antiatherosclerotic and Cardioprotective Potential of Acacia senegal Seeds in Diet-Induced Atherosclerosis in Rabbits. 2014;

37. Benzie IFF SJ. The Ferric Reducing Ability of Plasma (FRAP) as a Measure of "'Antioxidant Power"': The FRAP Assay. Anal Biochem. 1996;239:7-76. 
38. Hadwan MH. Simple spectrophotometric assay for measuring catalase activity in biological tissues. BMC Biochem. BMC Biochemistry; 2018;19:1-8.

39. Nandi A, Chatterjee IB. Assay of superoxide dismutase activity in animal tissues. J Biosci. 1988;13:305-15.

40. Rahman I, Kode A, Biswas SK. Assay for quantitative determination of glutathione and glutathione disulfide levels using enzymatic recycling method. Nat Protoc. 2007;1:3159-65.

41. Buege JA, Aust SD. Microsomal Lipid Peroxidation. Methods Enzymol. 1978;52:302-10.

42. Matthews DR, Hosker JP, Rudenski a S, Naylor B a, Treacher DF, Turner RC. Homeostasis model assessment: insulin resistance and beta-cell function from fasting plasma glucose and insulin concentrations in man. Diabetologia. 1985;28:412-9.

43. Parekh J, Jadeja D, Chanda S. Efficacy of Aqueous and Methanol Extracts of Some Medicinal Plants for Potential Antibacterial Activity. 2005;29:203-10.

44. Ram H, Jaipal N, Kumar P, Deka P, Kumar S, Kashyap P, et al. Dual Inhibition of DPP-4 and Cholinesterase Enzymes by the Phytocon- stituents of the Ethanolic Extract of Prosopis cineraria Pods: Therapeutic Implications for the Treatment of Diabetes-associated Neurological Impairments. Curr Alzheimer Res. 2019;16:1230-44.

45. Kaur J, Singla R, Jaitak V. In silico study of flavonoids as DPP-4 and a-glucosidase inhibitors. Lett Drug Des Discov. 2018;15:1-9.

46. Sneha P, Doss CGP. Gliptins in managing diabetes - Reviewing computational strategy. Life Sci [Internet]. Elsevier B.V.; 2016;166:108-20.

47. Reza Mohammadhassan, Sepideh Fallahi ZM. ADMET and pharmaceutical activity analysis of caffeic acid diversities by in silico tools. Lett Appl NanoBioScience. 2020;9:840-8.

48. Ubani A, Agwom F, Shehu NY, Luka P, Umera EA, Umar U, et al. Molecular Docking Analysis Of Some Phytochemicals On Two SARS-CoV-2 Targets. bioRxiv. 2020;25:1-14.

49. Assaad HI, Zhou L, Carroll RJ, Wu G. Rapid publication-ready MS-Word tables for one-way ANOVA. Springerplus. 2014;3:1-8.

50. Newsholme P, Krause M. Nutritional Regulation of Insulin Secretion: Implications for Diabetes. Clin Biochem Rev. 2012;33:35-47.

51. Chon S, Gautier JF. An update on the effect of incretin-based therapies on $\beta$-cell function and mass. Diabetes Metab J. 2016;40:99-114.

52. Donath MY, Ehses JA, Maedler K, Schumann DM, Ellingsgaard H, Eppler E, et al. Mechanisms of BetaCell Death in Type 2 Diabetes. Diabetes. 2005;54:2-7.

53. Kupsal K SM et al. Glucotoxicity and lipotoxicity induced beta-cell apoptosis in type 2 diabetes mellitus. International Journal of Analytical Bio-Science, 2015;4:84-89.

54. Srivastava S, Shree P, Tripathi YB. Active phytochemicals of Pueraria tuberosa for DPP-IV inhibition: In silico and experimental approach. J Diabetes Metab Disord. BioMed Central Ltd.; 2017;16:1-9. 
55. Kalhotra P, Chittepu VCSR, Osorio-Revilla G, Gallardo-Velazquez T. Phytochemicals in garlic extract inhibit therapeutic enzyme DPP-4 and induce skeletal muscle cell proliferation: A possible mechanism of action to benefit the treatment of diabetes mellitus. Biomolecules. 2020;10:1-16.

56. Akhtar N, Ihsan-ul-Haq, Mirza B. Phytochemical analysis and comprehensive evaluation of antimicrobial and antioxidant properties of 61 medicinal plant species. Arab J Chem [Internet]. King Saud University; 2018;11:1223-35.

57. Lankatillake C, Huynh T, Dias DA. Understanding glycaemic control and current approaches for screening antidiabetic natural products from evidence-based medicinal plants. Plant Methods [Internet]. BioMed Central; 2019;15:1-35.

58. Almasri IM, Mohammad MK, Taha MO. Inhibition of dipeptidyl peptidase IV by fexofenadine: Virtual screening study. J Appl Pharm Sci. Open Science Publishers LLP Inc. editor@japsonline.com; 2019;9:28-32.

59. Ekayanti M, Sauriasari R, Elya B. Dipeptidyl peptidase IV inhibitory activity of fraction from white tea ethanolic extract (Camellia sinensis (L.) Kuntze) ex vivo. Pharmacogn J. 2018;10:190-3.

60. Kato E, Kawakami K, Kawabata J. Macrocarpal C isolated from Eucalyptus globulus inhibits dipeptidyl peptidase 4 in an aggregated form. J Enzyme Inhib Med Chem. 2018;33:106-9.

61. Lacroix IME, Li-Chan ECY. Inhibition of dipeptidyl peptidase (DPP)-IV and a-glucosidase activities by pepsin-treated whey proteins. J Agric Food Chem. 2013;61:7500-6.

62. Ran Y, Pei H, Shao M, Chen L. Synthesis, Biological Evaluation, and Molecular Docking of (R)-2-((8-(3aminopiperidin-1-yl)-3-methyl-7-(3-methylbut-2-en-1-yl)-2,6-dioxo-2,3,6,7-tetrahydro-1 H-purin-1yl)methyl)benzonitrile as Dipeptidyl Peptidase IV Inhibitors. Chem Biol Drug Des. 2016;87:290-5.

63. Dias-Souza M V, Dias CG, Ferreira-Marçal PH. Interactions of natural products and antimicrobial drugs: Investigations of a dark matter in chemistry. Biointerface Res Appl Chem 2018;8:3259-64.

64. Majeed M, Majeed S, Mundkur L, Nagabhushanam K, Arumugam S, Beede K, et al. Standardized Emblica officinalis fruit extract inhibited the activities of a-amylase, a-glucosidase, and dipeptidyl peptidase-4 and displayed antioxidant potential. J Sci Food Agric. 2020;100:509-16.

65. Khanal P, Patil BM, Mandar BK, Dey YN, Duyu T. Network pharmacology-based assessment to elucidate the molecular mechanism of anti-diabetic action of Tinospora cordifolia. Clin Phytoscience. Clinical Phytoscience; 2019;5:1-9.

66. Meduru H, Wang Y, Tsai JJP, Chen Y. Finding a Potential Dipeptidyl Peptidase-4 ( DPP-4) Inhibitor for Type-2 Diabetes Treatment Based on Molecular Docking , Pharmacophore Generation , and Molecular Dynamics Simulation. 2016;4:1-12.

67. Patel BD, Bhadada S V., Ghate MD. Design, synthesis and anti-diabetic activity of triazolotriazine derivatives as dipeptidyl peptidase-4 (DPP-4) inhibitors. Bioorg Chem. 2017;72:345-58.

68. Lin SH, Huang KJ, Weng CF, Shiuan D. Exploration of natural product ingredients as inhibitors of human HMG-CoA reductase through structure-based virtual screening. Drug Des Devel Ther. 2015;9:3313-24. 


\section{Tables}

Table 1A: Identified masses from UPLC-QTOF mass spectroscopy constituents in the ethanolic fruit extract of Withania coagulans (Stocks) Dunal in positive electron ionization.

\begin{tabular}{|llllll|}
\hline S.No. & $\begin{array}{l}\text { Identified compound } \\
\text { Name }\end{array}$ & Formula & $\begin{array}{l}\text { Monoisotopic mass } \\
(\mathbf{g} / \mathbf{m o l})\end{array}$ & $\begin{array}{l}\text { Retention time } \\
(\mathbf{m i n})\end{array}$ & $\begin{array}{l}\mathbf{m + z} \\
\text { values }\end{array}$ \\
\hline 1. & Withanolide D & $\mathrm{C}_{28} \mathrm{H}_{38} \mathrm{O}_{6}$ & 470.6 & 7.66 & 471.6 \\
\hline 2. & Sitoindoside IX & $\mathrm{C}_{34} \mathrm{H}_{48} \mathrm{O}_{11}$ & 632.7 & 8.83 & 633.7 \\
\hline 3. & Withanoside IV & $\mathrm{C}_{40} \mathrm{H}_{62} \mathrm{O}_{15}$ & 782.9 & 9.66 & 783.7 \\
\hline 4. & Withanone & $\mathrm{C}_{28} \mathrm{H}_{37} \mathrm{O}_{6}$ & 469.6 & 11.97 & 469.5 \\
\hline 5. & Withanolide B & $\mathrm{C}_{28} \mathrm{H}_{38} \mathrm{O}_{5}$ & 454.6 & 12.33 & 455.5 \\
\hline 6. & Withaferine A & $\mathrm{C}_{28} \mathrm{H}_{38} \mathrm{O}_{6}$ & 470.6 & 15.02 & 471.4 \\
\hline
\end{tabular}

Table 1B: Identified masses from UPLC-QTOF mass spectroscopy constituents in the ethanolic fruit extract of Withania coagulans (Stocks) Dunal in negative electron ionization.

\begin{tabular}{|clllll|}
\hline S.No. & $\begin{array}{l}\text { Identified compound } \\
\text { Name }\end{array}$ & Formula & $\begin{array}{l}\text { Monoisotopic mass } \\
\text { (g/mol) }\end{array}$ & $\begin{array}{l}\text { Retention time } \\
\text { (min) }\end{array}$ & $\begin{array}{l}\text { m-z } \\
\text { values }\end{array}$ \\
\hline 1. & Withasomnine & $\mathrm{C}_{12} \mathrm{H}_{12} \mathrm{~N}_{2}$ & 184.24 & 7.11 & 183.2 \\
\hline 2. & Withangulatin $\mathrm{A}$ & $\mathrm{C}_{30} \mathrm{H}_{38} \mathrm{O}_{8}$ & 526.6 & 10.38 & 525.5 \\
\hline 3. & Withacoagulin $\mathrm{H}$ & $\mathrm{C}_{28} \mathrm{H}_{36} \mathrm{O}_{6}$ & 468.6 & 10.38 & 445.5 \\
\hline 4. & Withanolide E & $\mathrm{C}_{28} \mathrm{H}_{38} \mathrm{O}_{7}$ & 486.6 & 11.98 & 485.5 \\
\hline
\end{tabular}

Table 2: Molecular interactions of DPP-4 enzyme with detected compounds by LC-MS, present in ethanolic fruit extract of Withania coagulans (Stocks) Dunal 


\begin{tabular}{|c|c|c|c|c|c|}
\hline $\begin{array}{l}\text { S. } \\
\text { No. }\end{array}$ & Ligand & $\begin{array}{l}\text { Binding } \\
\text { Energy } \\
\text { (Kcal/mol) }\end{array}$ & $\begin{array}{l}\text { No. of } \\
\text { H- } \\
\text { bonds }\end{array}$ & Bond length $(\AA)$ & Interacting residues \\
\hline \multicolumn{6}{|c|}{ Positive control } \\
\hline 1. & Sitagliptin & -8.9 & 2 & $3.3,2.2$ & Glu205, Ser630 \\
\hline \multicolumn{6}{|c|}{ Phytoconstituents } \\
\hline 2. & Withanolide D & -9.2 & 1 & 2.1 & Val207 \\
\hline 3. & $\begin{array}{l}\text { Sitoindoside } \\
\text { IX }\end{array}$ & -9.8 & 4 & $2.4,3.3,(3.2,3.3)$ & Glu205, His740, Tyr547 \\
\hline 4. & $\begin{array}{l}\text { Withanoside } \\
\text { IV }\end{array}$ & \multicolumn{4}{|c|}{ Conformer generation is disallowed as too many atoms } \\
\hline 5. & Withanone & -7.9 & 4 & $(3.3,3.4), 1.4,2.3$ & Arg125, Tyr662, Val656 \\
\hline 6. & Withanolide B & -9.5 & 2 & $3.1,1.4$ & Tyr547, His740 \\
\hline 7. & Withaferine A & -8.1 & 2 & $2.1,2.4$ & Ser209 \\
\hline 8. & Withasomnine & -6.6 & 1 & 2.5 & Glu206 \\
\hline 9. & $\begin{array}{l}\text { Withangulatin } \\
\text { A }\end{array}$ & -8.8 & 8 & $\begin{array}{l}3.2,(3.2,3.6),(3.2 \\
3.3)(3.2,3.3), 3.2\end{array}$ & $\begin{array}{l}\text { Ser209, Arg125, } \\
\text { Glu205, Glu206, Tyr662 }\end{array}$ \\
\hline 10. & $\begin{array}{l}\text { Withacoagulin } \\
\mathrm{H}\end{array}$ & -8.9 & 1 & $2.4,2.9,2.1,2.3,1.6$ & $\begin{array}{l}\text { Glu206, Ser209, } \\
\text { Tyr547, Glu205, } \\
\text { Asp663 }\end{array}$ \\
\hline 11. & Withanolide E & -7.6 & 4 & $2.8,3.4,3.4,3.2$ & $\begin{array}{l}\text { Glu206, Ser209, } \\
\text { Asn710, His740 }\end{array}$ \\
\hline
\end{tabular}

Table 3: ADMET Pharmacokinetics of detected phytoconstituents of ethanolic fruit extract of Withania coagulans (Stocks) Dunal prediction by Drulito against Lipinski rule of five and blood-brainbarrier filter 


\begin{tabular}{|lllllllllll|}
\hline Compound & MW & $\log P$ & AlogP & HBA & HBD & TPSA & nHB & $\begin{array}{l}\text { nAcidic } \\
\text { group }\end{array}$ & $\begin{array}{c}\text { Filter } \\
\text { L/B }\end{array}$ \\
\hline Withanolide D & 470.27 & 3.263 & 1.293 & 6 & 2 & 96.36 & 8 & 0 & L \\
\hline Sitoindoside IX & 632.32 & 2.45 & -1.105 & 11 & 5 & 175.51 & 16 & 0 & \\
\hline Withanoside IV & 102.07 & 1.311 & -0.73 & 2 & 1 & 37.3 & 3 & 1 & L \\
\hline Withanone & 470.27 & 2.153 & 0.828 & 6 & 2 & 96.36 & 8 & 1 & $\mathrm{~L}$ \\
\hline Withanolide B & 454.27 & 4.118 & 1.539 & 5 & 1 & 76.13 & 6 & 0 & $\mathrm{~L}$ \\
\hline Withaferine A & 470.27 & 3.987 & 0.642 & 6 & 2 & 96.36 & 8 & 0 & $\mathrm{~L}$ \\
\hline Withasomnine & 184.1 & 2.436 & 0.991 & 2 & 0 & 15.6 & 2 & 0 & $\mathrm{~L} / \mathrm{B}$ \\
\hline $\begin{array}{l}\text { Withangulatin } \\
\text { A }\end{array}$ & 526.26 & 1.126 & 0.685 & 8 & 2 & 122.66 & 10 & 0 & \\
\hline $\begin{array}{l}\text { Withacoagulin } \\
\text { H }\end{array}$ & 468.25 & 1.903 & 1.021 & 6 & 3 & 104.06 & 9 & 0 & $\mathrm{~L}$ \\
\hline Withanolide E & 486.23 & 1.363 & 0.444 & 7 & 3 & 116.59 & 10 & 0 & $\mathrm{~L}$ \\
\hline
\end{tabular}

$M W=$ molecular weight; $\log P=$ partition coefficient; $A \log P=$ octanol-water partition coefficient; $H B A=$ hydrogen bond acceptor; $H B D=$ hydrogen bond donor; $T P S A=$ total polar surface area; $n H B=$ number of hydrogen bond; $n$ Acidic group = number of acidic group; Filter $L=$ Lipinski rule of five and $B=$ blood brain barrier

Figures 

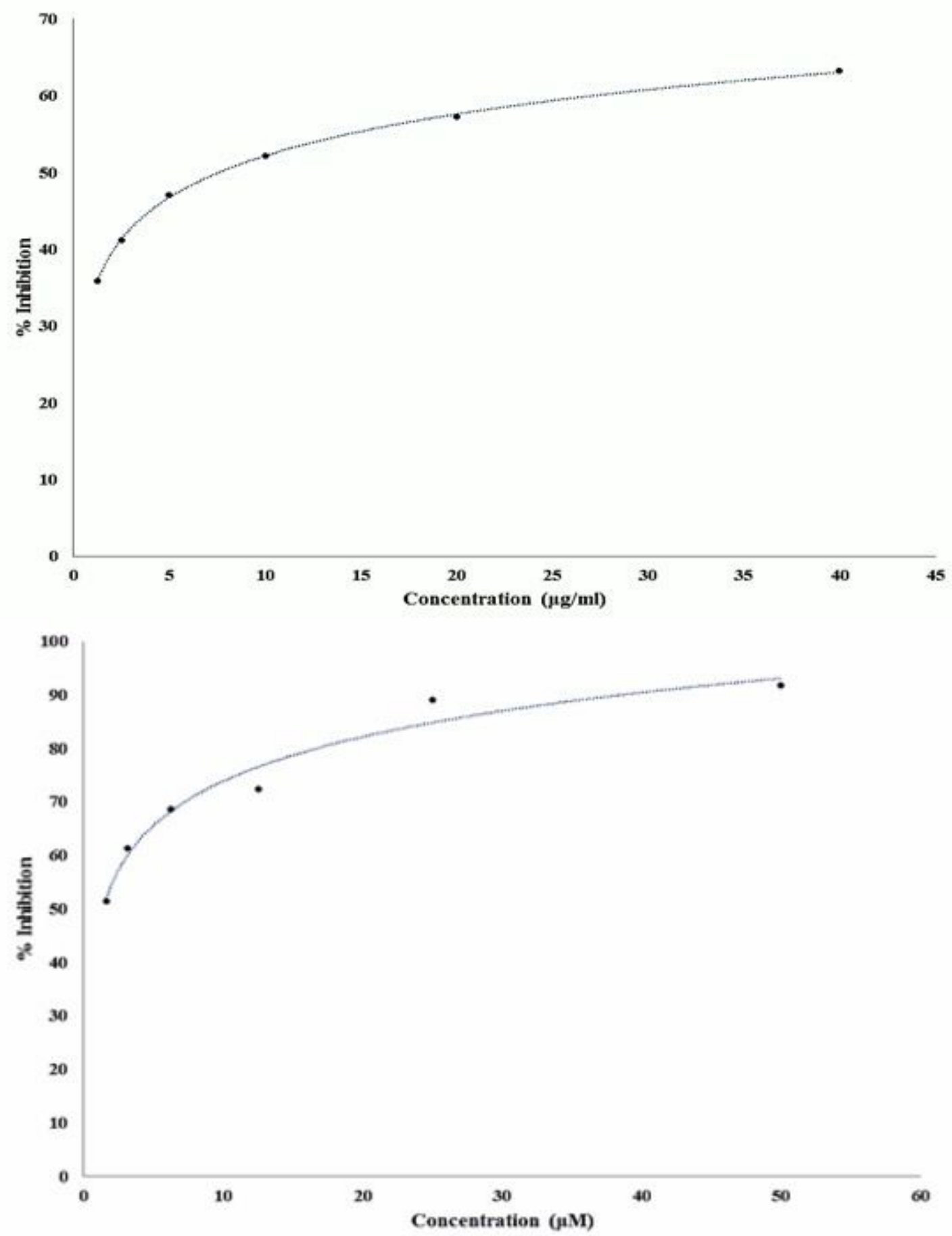

\section{Figure 1}

(Top) A: In-vitro DPP-4 inhibition assay against ethanolic fruit extract of ethanol fruit extract of Withania coagulans (Equation- $y=7.8441 \ln (x)+34.107, R^{2}=0.9995, I C 50=7.58 \mu \mathrm{g} / \mathrm{ml}$ ) (Bottom) 1B: In-vitro DPP-4 inhibition assay against sitagliptin (Equation $-y=11.953 \ln (x)+46.305, R^{2}=0.9671, I C 50=1.36 \mu M$ ) 
5

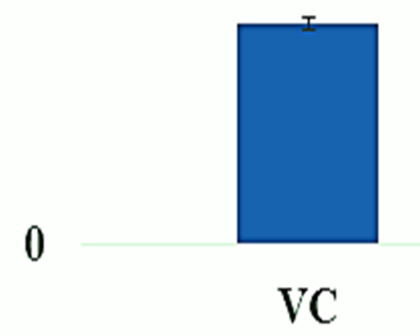

DC
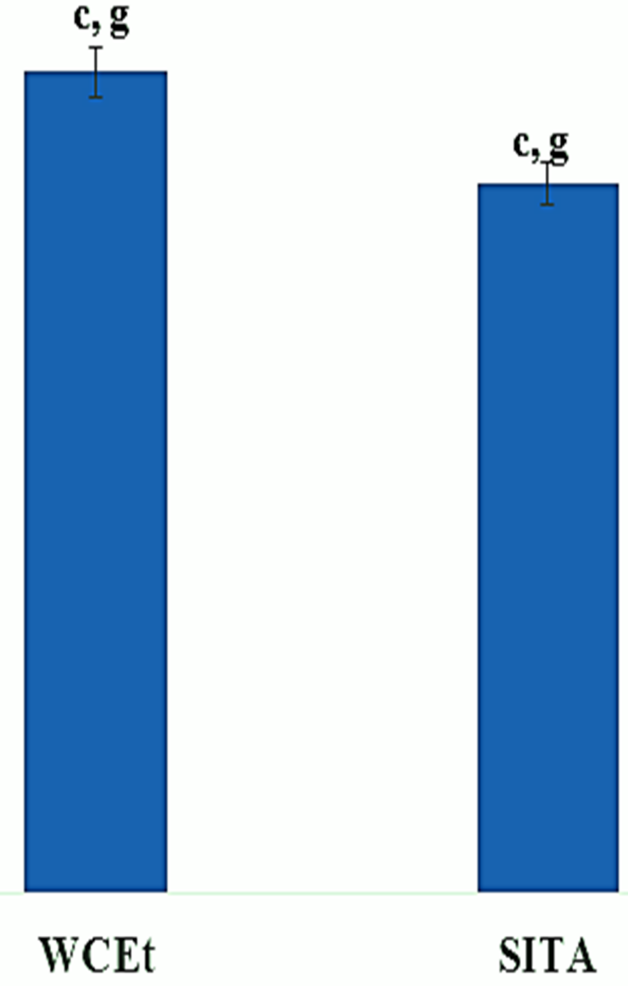

Figure 2

Serum DPP-4 levels in control and treatment groups. Data are means \pm S.E.M. $(n=6) ; \mathrm{c}, P \leq 0.001$; and d non-significant as compared to the respective control values.; $g, P \leq 0.001$; and $\mathrm{h}$ non-significant as compared to the respective values of the diabetic control group. 


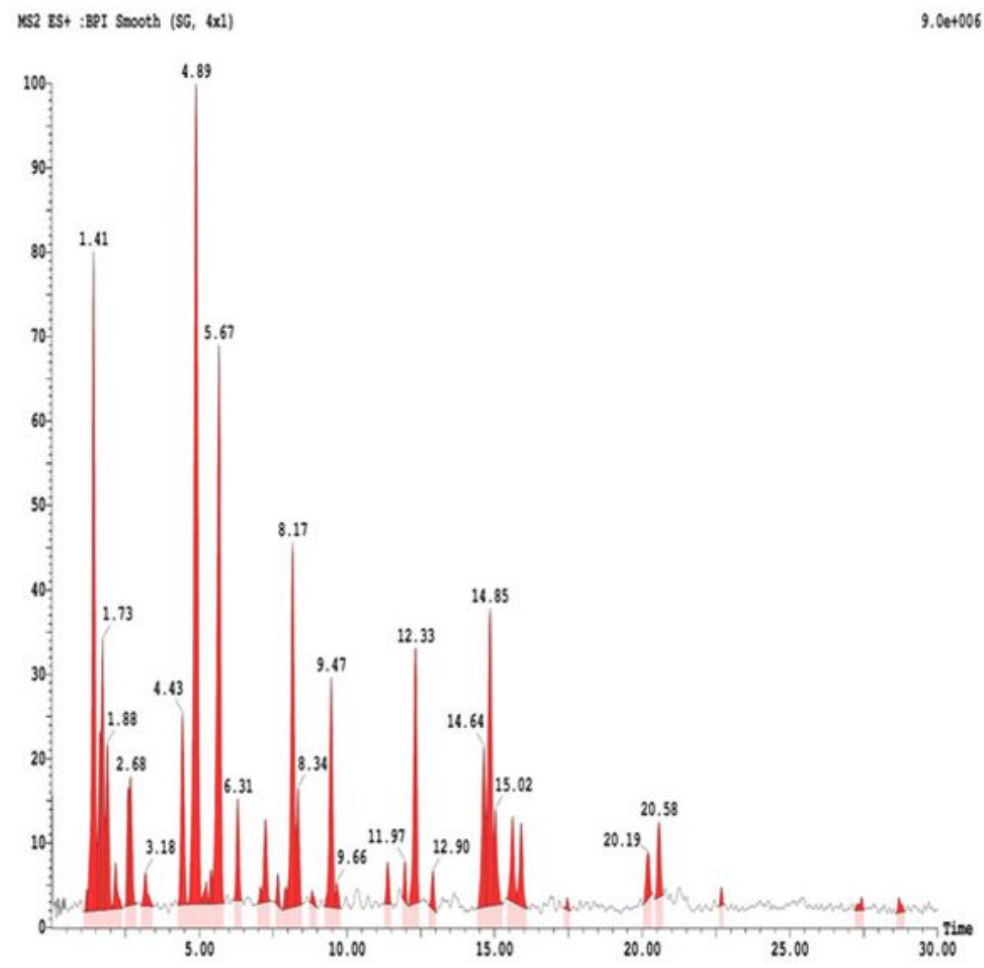

2: XS2 ES- :BPI Snooth $(S 6,4 \times 1)$

$5.7 e+005$

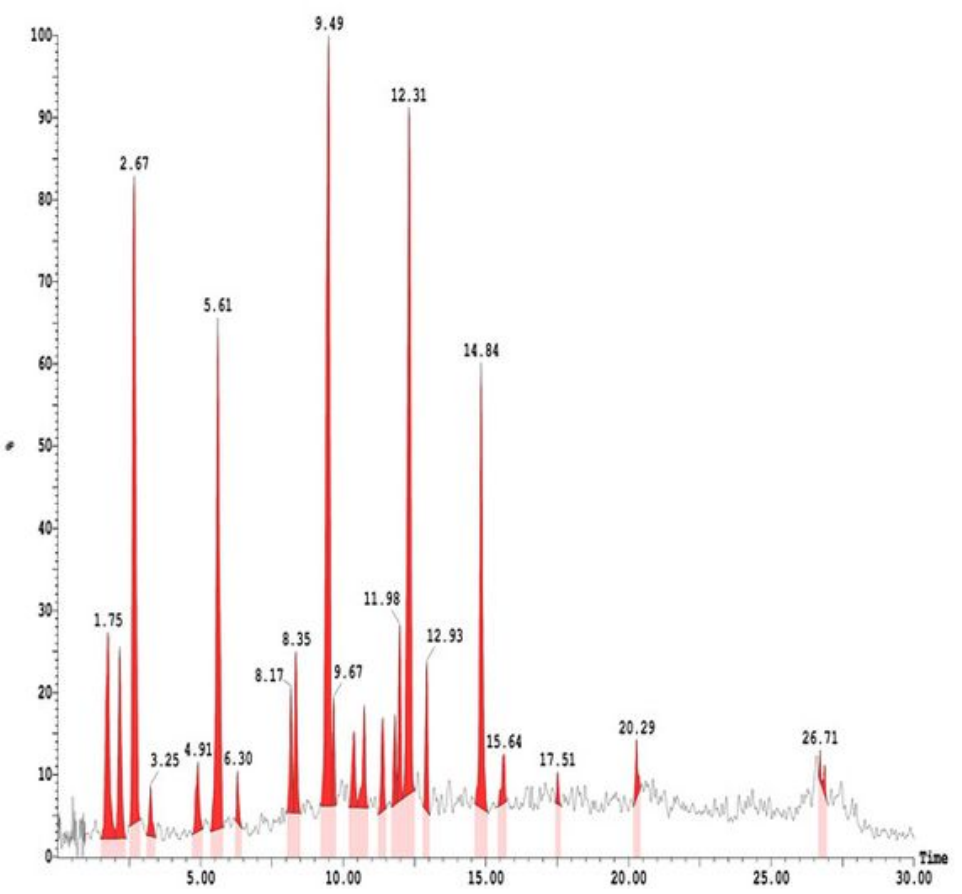

Figure 3

(Top) A: QTOF of ethanol fruit extract of Withania coagulans (Bottom) B: QTOF of ethanol fruit extract of Withania coagulans 


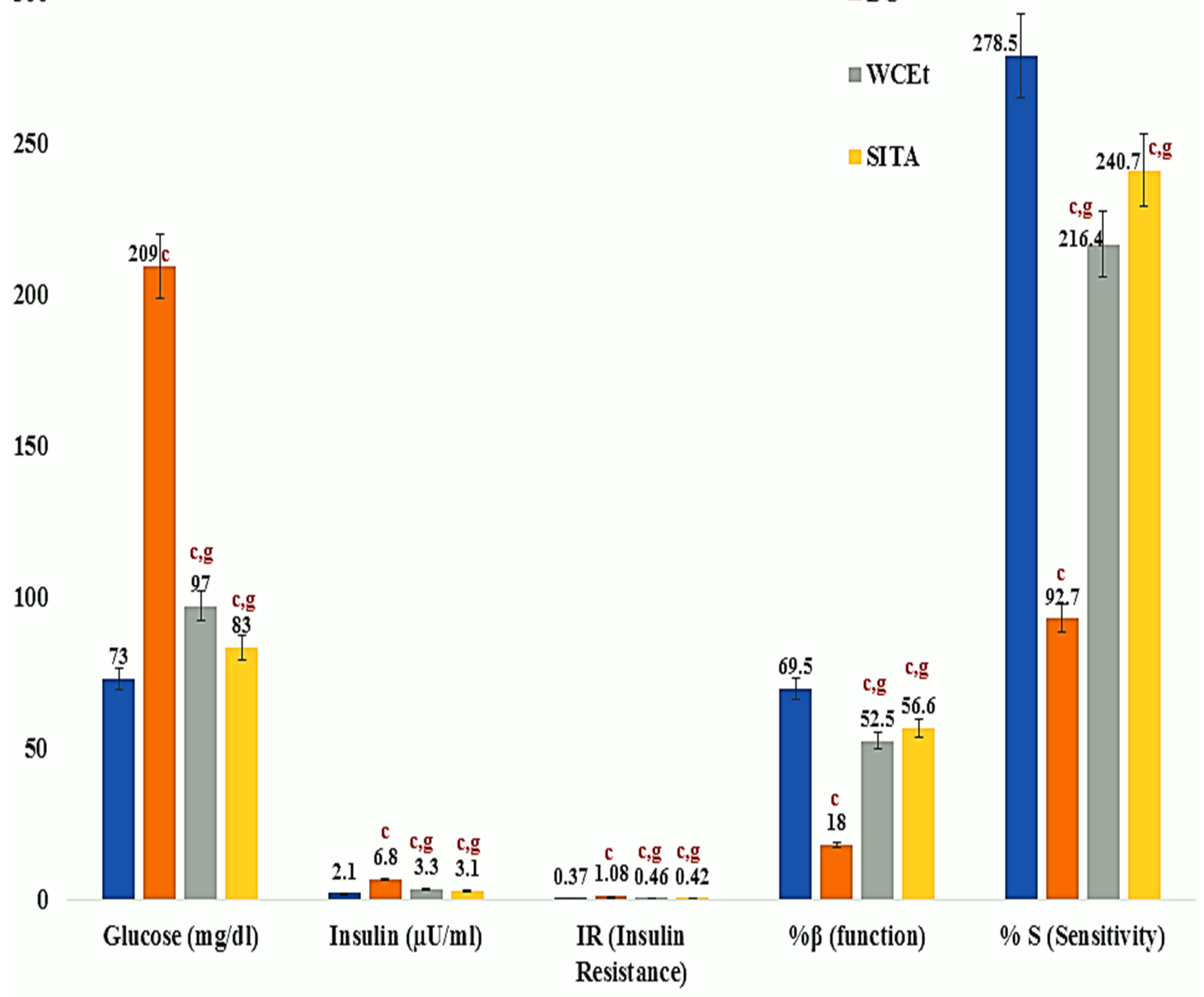

Figure 4

Effect of ethanol fruit extract of Withania coagulans on glucose homeostasis Data are means \pm S.E.M. ( $n$ = 6); c, $P \leq 0.001$; and d non-significant as compared to the respective control values.; $\mathrm{g}, P \leq 0.001$; and $\mathrm{h}$ non-significant as compared to the respective values of the diabetic control group. 
200

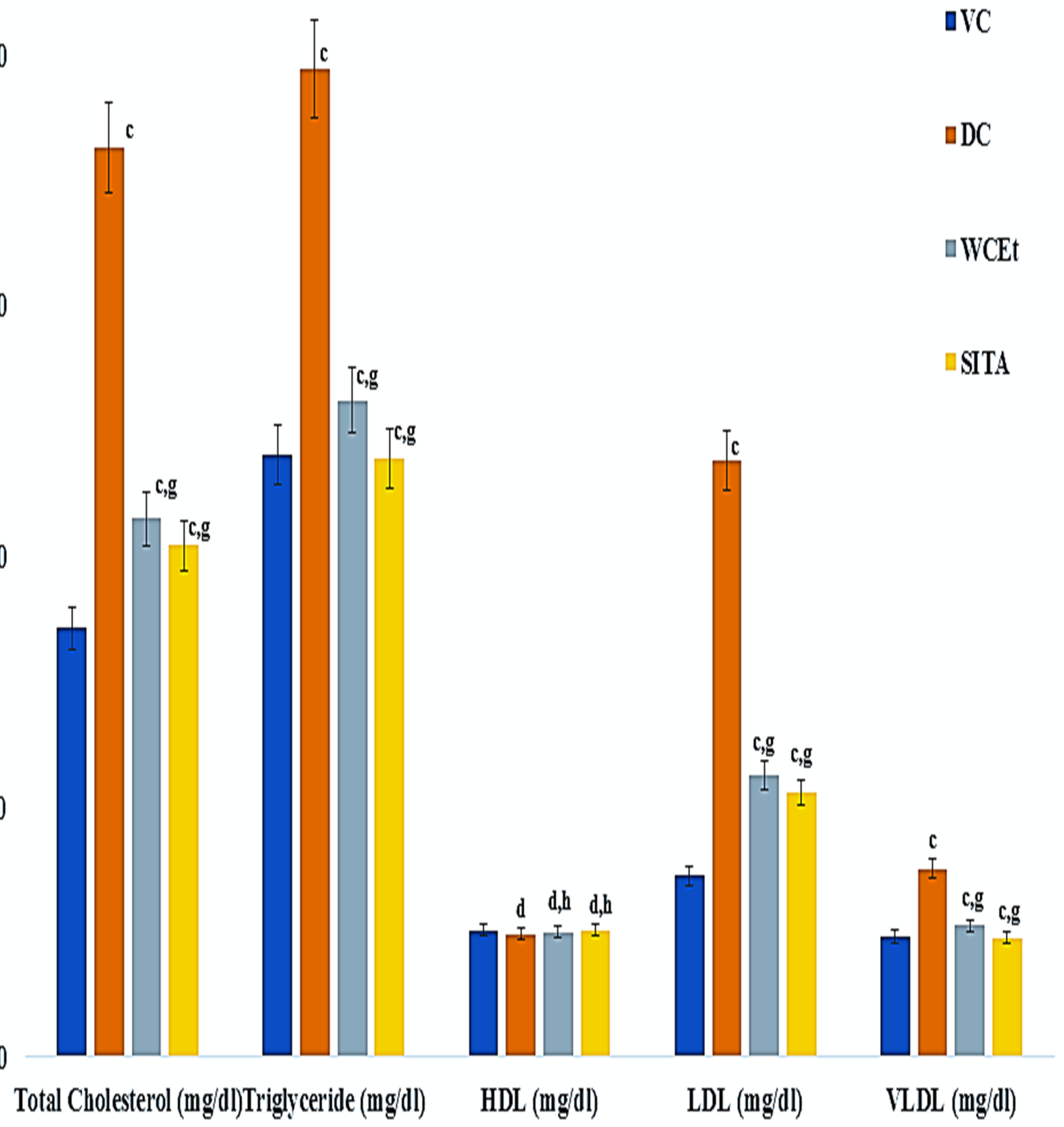

Figure 5

Effect of ethanol fruit extract of Withania coagulans on lipid profile Data are means \pm S.E.M. $(n=6) ; c, P$ $\leq 0.001$; and $d$ non-significant as compared to the respective control values. $\mathrm{h}$ non-significant as compared to the respective values of the diabetic control group. 
$\square \mathrm{VC}$

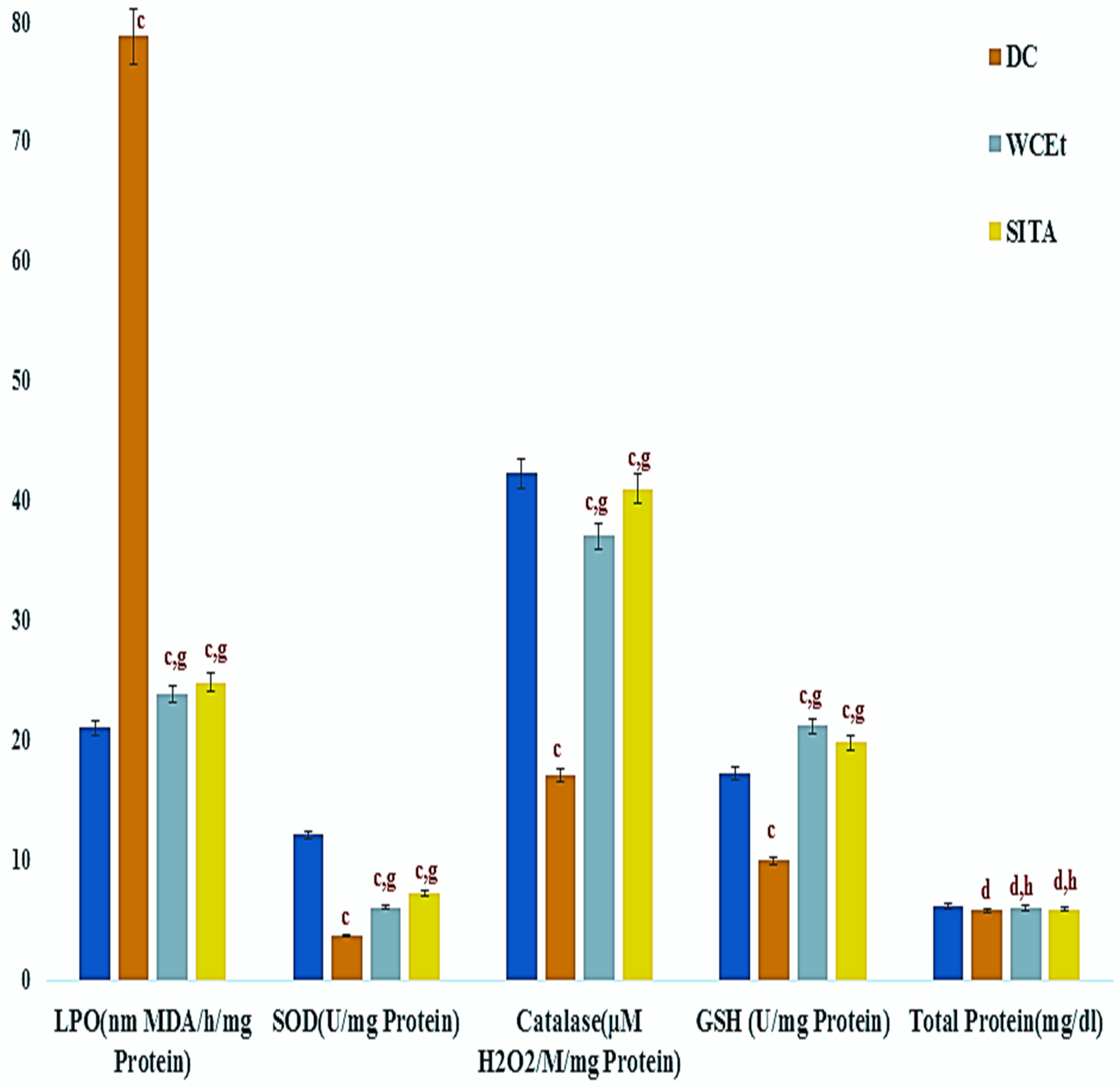

\section{Figure 6}

Effect of ethanol fruit extract of Withania coagulans Dunal on antioxidant levels Data are means \pm S.E.M. $(n=6) ; c, P \leq 0.001$; and d non-significant as compared to the respective control values. e, $P \leq 0.05 ; \mathrm{g}$, $P \leq 0.001$; and $\mathrm{h}$ non-significant as compared to the respective values of the diabetic control group. 


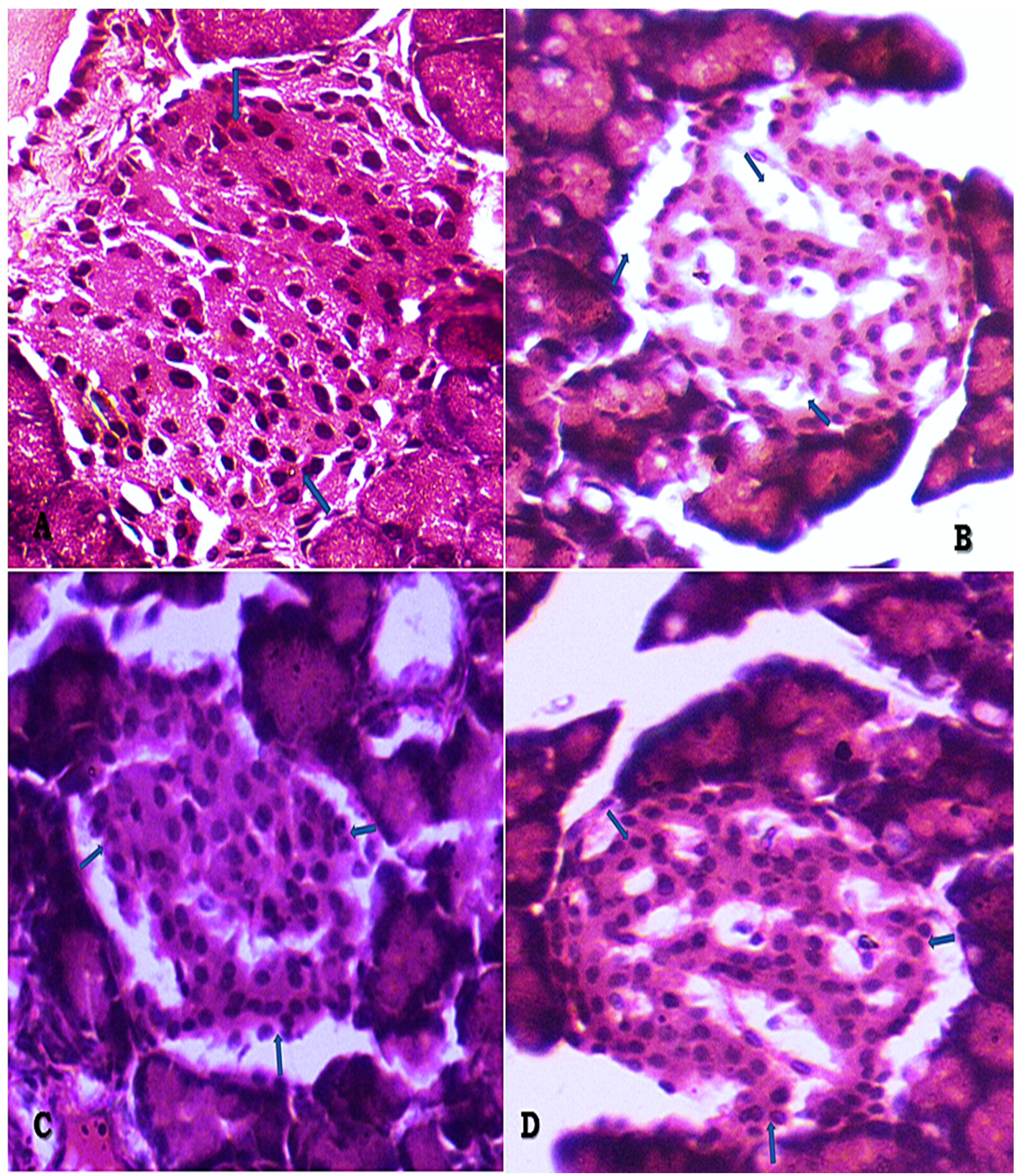

Figure 7

A-D: Histology of different control and treatment groups (400X H\&E): Arrows indicates the peripheral $\beta$ cell rich area with organised cellular mass of islet of the Langerhans (7A), degenerative area pointed by arrow (7B), arrow indicating the increased cellular mass (7C) and organized cellular mass pointed by arrow. 


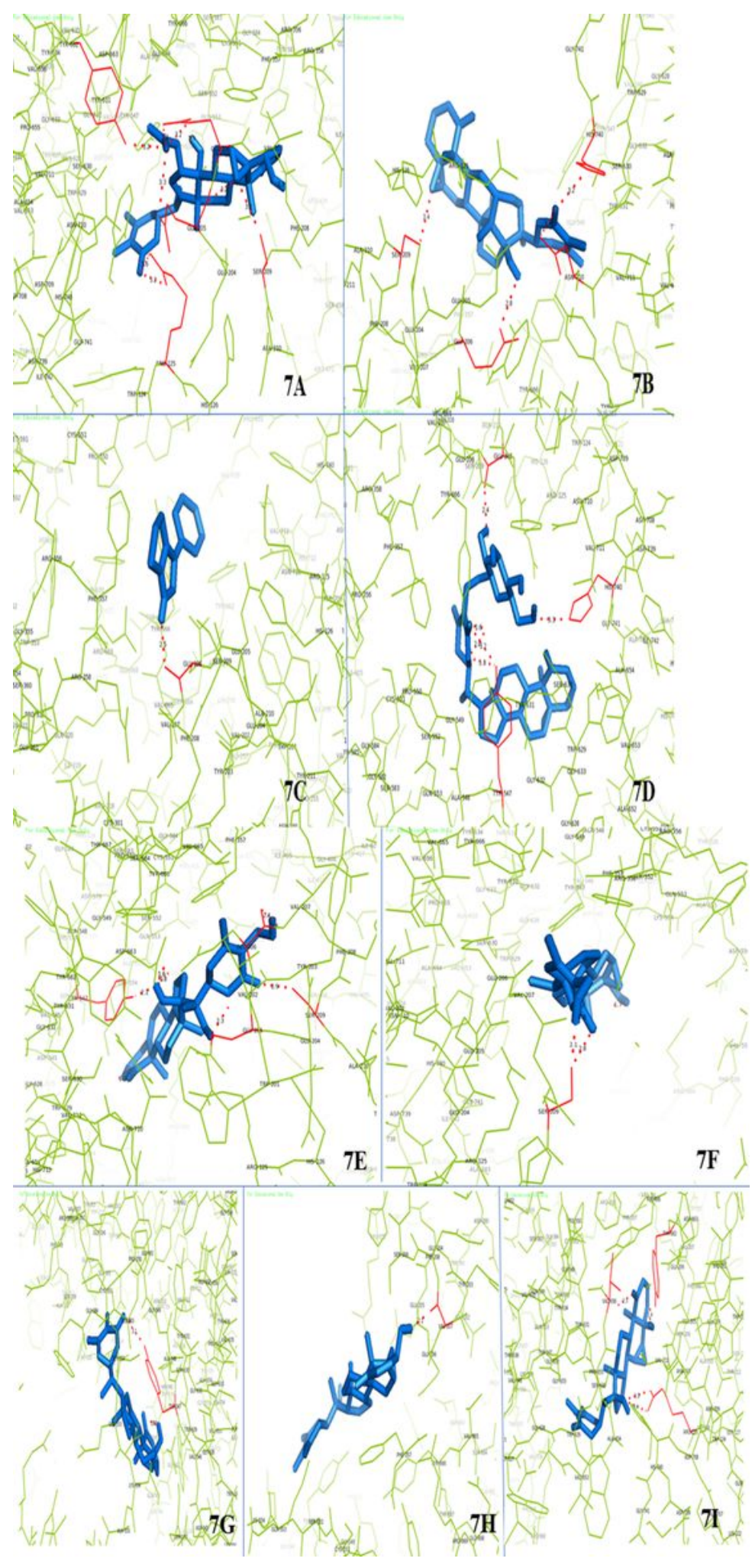

\section{Figure 8}

8A: DPP4 interaction with withangulatinA, Figure 8B: DPP4 interaction with withanolide E, Figure 8C: DPP4 interaction with withasomnine, Figure 8D: DPP4 interaction with sitoindoside IX 8E: DPP4 interaction with withacoagulin H; Figure 8F: DPP4 interaction with withaferine A; Figure 8G: DPP4 interaction with withanolide B; Figure 8H: DPP4 interaction with withanolide D; Figure 8I: DPP4 interaction with withanone 


\section{Supplementary Files}

This is a list of supplementary files associated with this preprint. Click to download.

- HighSucrosedietcomposition.docx 